Saudi Journal of Business and Management Studies Abbreviated Key Title: Saudi J Bus Manag Stud ISSN 2415-6663 (Print) |ISSN 2415-6671 (Online) Scholars Middle East Publishers, Dubai, United Arab Emirates Journal homepage: https://saudijournals.com

Original Research Article

\title{
Quantitative Analysis of Diffusion of Public Opinion by the Modified Bass Model for the Dyeing Steamed Bread Incident in China
}

\author{
Lang Liang ${ }^{1},{ }^{2 *}$
}

${ }^{1}$ School of Management, Hefei University of Technology, Hefei 230009, China

${ }^{2}$ School of Management, Henan University of Technology, Zhengzhou 450001, China

\begin{tabular}{lr}
\hline $\begin{array}{l}\text { DOI: } 10.36348 / \text { sjbms.2021.v06i01.004 } \\
\text { *Corresponding author: Lang Liang }\end{array}$ & | Received: 17.01.2021 | Accepted: 25.01.2021 | Published: 30.01 .2021 \\
Email: lianglang_ed@aliyun.com
\end{tabular}

\section{Abstract}

The information diffusion of food safety incident is sometimes more serious than food safety incident itself, because this may lead to severe public opinion and affect purchase intention of individual consumer. Thus, it is very important to study the rule of information diffusion of food safety incident. In this work, a modified Bass diffusion (MBD) model including the role of government is proposed based on the characteristics of food safety information diffusion in China and its analytical solution is derived correspondingly. Such model is tested and validated by a specific case of food safety incident, that is, dyeing steamed bread incident happened in China. The results show that the present MBD model can effectively predict the diffusion of public opinion for food safety information and simultaneously the parameter analysis reveals that the government management to the quality and credibility of information is critical in improving the communication of food safety information.

Keywords: Food safety; Information diffusion; Modified Bass diffusion model; Parameter estimation.

Copyright (C) 2021 The Author(s): This is an open-access article distributed under the terms of the Creative Commons Attribution 4.0 International License (CC BY-NC 4.0) which permits unrestricted use, distribution, and reproduction in any medium for non-commercial use provided the original author and source are credited.

\section{INTRODUCTION}

Information diffusion models and theories have been posed very early and many research findings have been achieved. Houser studied the relationship between news reports and people's perception of events from the perspective of communication [9]. On the basis of considering the influence factors of information sender and information receiver, Duggan et al. constructed the diffusion model of crisis information [4]. Genius et al., analyzed the role of information dissemination in the diffusion of agricultural irrigation technology [6]. Bray and Mendelson explained the bullwhip effect in product supply chain [2]. The influencing factors on food safety incidents had been mainly studied in China. Wang et al., analyzed the influencing factors of food safety and divided the influencing factors into four categories [18]. Ma et el., investigated some food safety incidents occurred in China and pointed out the main risk factors and responsibility subjects of food safety [12]. Liang proposed a two-way communication framework and a quantitative analysis of food safety risk factors is implemented based on this framework [11]. Hou put forward some countermeasures and suggestions to promote food quality and safety information transmission [8]. Based on the social impact theory and BASS model, Li et al., constructed the basic model of information diffusion for public dangerous chemicals hazard, which shown that government has driving action for information dissemination [10]. He et al., summarized the problems existing in the construction of food safety information system in China and gave some suggestions on the construction of food safety information system [7].

The information diffusion is mainly studied in the field of communication and information science [15]. There are very few researches on the diffusion of food safety information. The information diffusion of food safety incident is sometimes more serious than food safety accident itself, because the information asymmetry between food enterprise and consumers may lead to severe public opinion and affect purchase 
intention of individual consumer. Therefore, it is very important to study the information diffusion of food safety incident. Based on the BASS model, a modified BASS diffusion (MBD) model including the role of government is proposed. Then, the MBD model is tested and validated by simulating the information diffusion of dyeing steamed bread incident happened in China to reveal the role of government in improving the communication of food safety information.

\section{Incident Description}

The dyeing steamed bread (DSB) incident was happened at Shanghai City in China in 2011 [3]. The incident was disclosed by the official report of CCTV Financial Channel in April 10, 2011. The report said that Shanghai Shenglu Food Company arbitrarily changed the date of production, used expired raw materials and broke health standards in the producing process of steamed bread. The incident caused a big impact at that time in China and was listed as one of 20 Network hotspot events in 2011 in China [20]. Figure-1 shows the changing trend of the DSB incident gotten by searching the word "dyeing steamed bread" in Baidu, in which the vertical axis denotes the amount of daily increase of public opinion data. It can be seen from Figure-1 that the DSB incident developed rapidly in the first few days, and lasted about 20 days. It was finally subsided through the participation and management of Government.

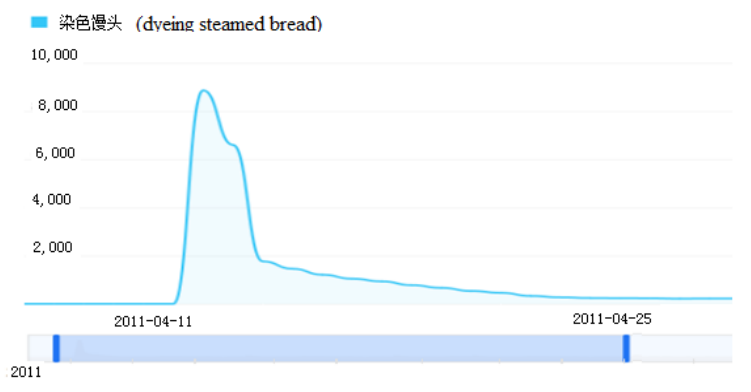

Fig-1: Trend of public opinion data for DSB Incident

\section{Modified BASS model \\ BASS Model}

BASS model was initially built by economists for the forecast of products and technology market. Assuming that the recipient is only affected by mass media, Fourt et al. proposed a forecasting model [5]. Lately, based on the assumption that the recipient is only affected by the oral communication, Manfield established a different forecasting model [13]. Then, based on a comprehensive understand of these studies, Bass believed that the recipients are affected by both mass media and oral communication, and so the following BASS model was proposed in 1969 as [1].

$$
\frac{\mathrm{d} y(t)}{\mathrm{d} t}=p(m-y(t))+q \frac{\mathrm{y}(t)}{m}[m-\mathrm{y}(t)] \ldots
$$

Where $y(t)$ stands for the cumulative number of people receiving risk information at time $t$. $\mathrm{d} y(t) / \mathrm{d} t$ stands for the rate of people receiving risk information at time $t . \mathrm{m}$ stands for the maximum number of potential risk recipients. $y(t) / m$ stands for the proportion of cumulative recipients of risk information versus potential recipients. $p$ stands for external (mass media) impact factor, $q$ stands for internal (oral communication) impact factors.

\section{Modified BASS Model}

The influence of government on information diffusion can not be ignored in China. But the BASS model contains only the influence of mass media and oral communication, so a modified BASS (MBD) model includes the influence of government is proposed as follows

$$
\frac{\mathrm{d} y(t)}{\mathrm{d} t}=p(m-y(t))+q \frac{\mathrm{y}(t)}{m}[m-\mathrm{y}(t)]-\alpha(m-y(t)) . .
$$

Eq. (2) can be rewritten in the following form

$$
\frac{\mathrm{d} y(t)}{(y(t)-m)}-\frac{\mathrm{d} y(t)}{\mathrm{y}(t)+\frac{\mathrm{m}(p-\alpha)}{q}}=-(p+q-\alpha) \mathrm{d} t \ldots \ldots
$$

Integrating both sides of Eq. (3) yields the general solution of Eq. (2)

$$
\frac{y(t)-m}{\mathrm{y}(t)+\frac{\mathrm{m}(p-\alpha)}{q}}=C \times e^{-(\mathrm{p}+\mathrm{q}-\alpha) t} .
$$

From the initial condition: $\left.y(t)\right|_{t=0}=0$, the constant $C$ in Eq. (4) can be determined by

$$
\mathrm{C}=\frac{q}{p-\alpha}
$$

Then, substituting Eq. (5) into Eq. (4), we have

$$
y(t)=m \frac{1-e^{-(\mathrm{p}+\mathrm{q}-\alpha) t}}{1+\frac{q}{p-a} e^{-(\mathrm{p}+\mathrm{q}-\alpha) t}}
$$

Obviously, once the parameters in Eq. (6) are determined, the cumulative number of people receiving risk information at any time can be calculated.

\section{Simulation and Analysis of Public Opinion Diffusion Data of Public Opinion Diffusion}

The data of daily increment (DODI) in public opinion from April 11 to April 30 can be gotten from Figure-1. The data of daily accumulation (DODA) can be calculated out from the DODI. The DODI and DODA are listed in the columns 3 and 4 of Table-1, respectively. Columns 1 and 2 of Table- 1 are dates and serial numbers of dates, respectively. The amount of DODA in the column 4 will be used to estimate the parameters in Eq. (6). 
Table-1: Data of curves

\begin{tabular}{|l|l|l|l|l|l|l|}
\hline Date & $\begin{array}{l}\text { Serial } \\
\text { number }\end{array}$ & DODI & $\begin{array}{l}\text { Actual } \\
\text { DODA }\end{array}$ & $\begin{array}{l}\text { Simulated } \\
\text { DODA }\end{array}$ & Case-a & Case-b \\
\hline $11 / 11$ & 1 & 236 & 236 & 5,520 & 1,450 & 1,240 \\
\hline $12 / 11$ & 2 & 5,622 & 5,858 & 14,140 & 3,830 & 2,760 \\
\hline $13 / 11$ & 3 & 13,544 & 19,400 & 26,860 & 7,670 & 4,600 \\
\hline $14 / 11$ & 4 & 24,046 & 43,450 & 44,160 & 13,710 & 6,840 \\
\hline $15 / 11$ & 5 & 23,035 & 66,480 & 65,240 & 22,840 & 9,530 \\
\hline $16 / 11$ & 6 & 21,500 & 87,980 & 87,740 & 35,840 & 12,750 \\
\hline $17 / 11$ & 7 & 21,100 & 109,100 & 108,620 & 52,880 & 16,570 \\
\hline $18 / 11$ & 8 & 21,112 & 120,200 & 125,610 & 72,930 & 21,050 \\
\hline $19 / 11$ & 9 & 8,026 & 138,200 & 138,030 & 93,740 & 26,240 \\
\hline $20 / 11$ & 10 & 5,139 & 143,400 & 146,400 & 112,700 & 32,180 \\
\hline $21 / 11$ & 11 & 3,920 & 147,300 & 151,750 & 128,030 & 38,870 \\
\hline $22 / 11$ & 12 & 2,874 & 150,200 & 155,040 & 139,280 & 46,270 \\
\hline $23 / 11$ & 13 & 2,757 & 152,900 & 157,030 & 146,950 & 54,300 \\
\hline $24 / 11$ & 14 & 2,345 & 155,300 & 158,210 & 151,930 & 62,830 \\
\hline $25 / 11$ & 15 & 2,353 & 157,500 & 158,910 & 155,060 & 71,690 \\
\hline $26 / 11$ & 16 & 1,865 & 159,400 & 159,320 & 156,980 & 80,690 \\
\hline $27 / 11$ & 17 & 1,924 & 161,300 & 159,560 & 158,150 & 89,600 \\
\hline $28 / 11$ & 18 & 1,564 & 162,900 & 159,700 & 158,850 & 98,230 \\
\hline $29 / 11$ & 19 & 1,365 & 164,300 & 159,790 & 159,280 & 106,400 \\
\hline $30 / 11$ & 20 & 1,721 & 166,100 & 159,840 & 159,530 & 113,960 \\
\hline
\end{tabular}

\section{Parameter Estimation}

In order to simulate the diffusion of public opinion by the present MBD model, the parameters $m, p, q$ and $\alpha$ in Eq (6) need to be estimated. The commonly used parameter estimation methods are ordinary least square (OLS) method [19], nonlinear least squares (NLS) method [17], maximum-likelihood estimation (MLE) method [16] and genetic algorithms (GA) [14], etc. Because the solution of Eq. (6) is a nonlinear function, the NLS method is used to estimate the parameters. The parameters in Eq. (6) are estimated based on the data of the column 4 in Table- 1 . The estimated results of parameters in Eq. (6) are listed in Table-2. Because $R^{2}=0.995$, it is indicated that the estimated parameters have good fitting degree.

Table-2: The results of parameter estimation

\begin{tabular}{|l|l|l|}
\hline Parameter & Initial value & Estimated value \\
\hline $\mathrm{m}$ & 159840 & 159903 \\
\hline $\mathrm{p}$ & 0.6 & 0.541 \\
\hline $\mathrm{q}$ & 0.6 & 0.511 \\
\hline $\mathrm{a}$ & 0.59 & 0.514 \\
\hline $\mathrm{R}^{2}$ & & 0.995 \\
\hline
\end{tabular}

\section{Simulation of Public Opinion Diffusion}

The simulated DODA, which is listed in the column 5 of Table-1, can be obtained by substituting the estimated parameters in Table-2 into Eq. (6). For the purpose of comparison of the simulated DODA with the actual DODA, Figure-2 displays their curves in terms of time (unit: day), respectively. It can be seen from Figure-2 that: (1) the curve of simulated DODA almost coincides with that of actual MODA, so the modified BASS Model can be used to predict public opinion effectively, and (2) the fastest growing interval for public opinion is days $4-8$, which is the key time to control public opinion.

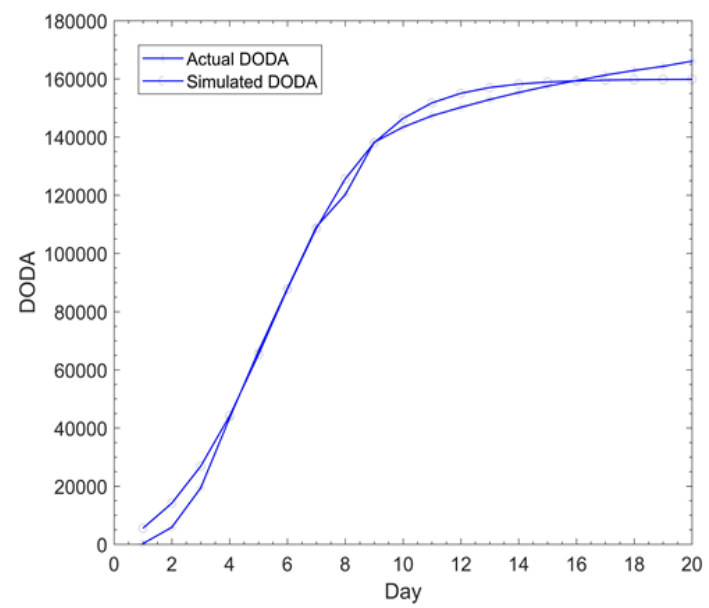

Fig-2: Curves of actual and simulated DODA

The Modified BASS Model can be used to analyze the influence of different parameters and their combinations on public opinion. Here two cases are given. (a) Case-a: letting the parameter $\alpha=0.534$ and other parameters are kept constant, and (b) Case-b: letting the parameter $\alpha=0.534, q=0.211$ and other parameters are kept constant. The curves of Case$a$ and Case-b are plotted in Figure-3. For comparison, the curve of actual DOMA is also drawn in Figure-3. It can be seen from Figure-3 that: (1) the influences of parameters $\alpha$ and $q$ on the public opinion are significant, and (2) the feasible strategies and methods for controlling public opinion can be made by the government in practice to improve the communication 
Lang Liang., Saudi J Bus Manag Stud, Jan, 2021; 6(1): 24-27

of food safety information based on analyzing and comparing the influence of parameters on public opinion.

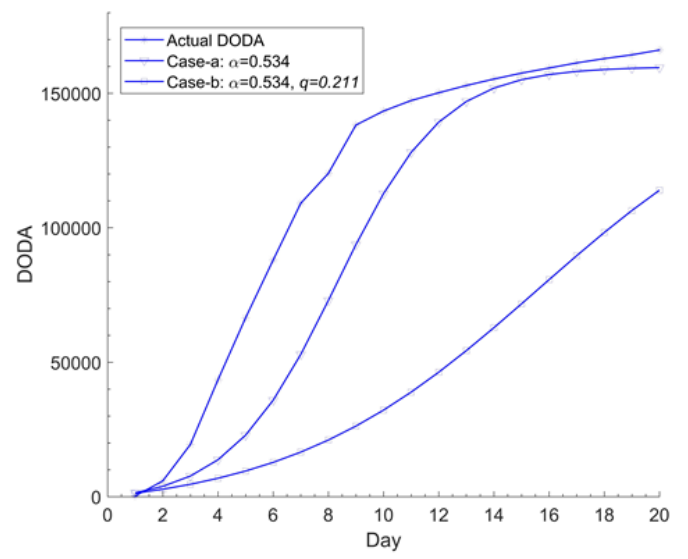

Fig-3: Influence of parameters on public opinion

\section{CONCLUSIONS}

Considering the characteristics of food safety information diffusion, a MBD model including the role of government is proposed and the related analytical solution of the model is derived. Then, the parameters of MBD model are estimated by using the function of OLS method for a specific case of dyeing steamed bread incident. For this incident, the variation of public opinion data in terms of time is simulated by substituting the estimated parameters into the analytical solution of the MBD model. The simulated results are of good agreement with the actual variation, which shows that the MBD model proposed in this paper can be used to predict the diffusion of public opinion on food safety events. Further, the parameter analysis indicates it is suggested that the government can make proper strategies and methods to improve the communication to public opinion.

Conflicts of Interest: The author declares no conflict of interest.

\section{REFERENCES}

1. Bass, F. M. (1969). A New Product Growth Model for Consumer Durable. Management Science, 15(5), 215-227.

2. Bray, R. L., \& Mendelson, H. (2012). Information Transmission and the Bullwhip Effect: An Empirical Investigation. Management Science, 58(5), 860-875.

3. China Food and Drug Administration, National Center for Food Safety Risk Assessment. Theoretical exploration of food safety risk (in Chinese). (2015). Beijing: China Quality Inspection Press.

4. Duggan, F., \& Banwell, L. (2004). Constructing a model of effective information dissemination in a crisis. Information dissemination, Crisis, Crises, Tuberculosis, Dissemination of information, Metaethnographic analysis, Social marketing. Information Research: An International Electronic Journal, 9(3), 178-184.
5. Fourt, L. A., \& Woodlock, J. W. (1960). Early prediction of marker success for new crockery products. Journal of marketing, 25(2), 31-38.

6. Genius, M., Koundouri, P., Nauges, C., \& Tzouvelekas, V. (2014). Information Transmission in Irrigation Technology Adoption and Diffusion: Social Learning, Extension Services, and Spatial Effects. American Journal of Agricultural Economics, 96(1), 328-344.

7. He, H., Chen, Q. L., \& Hu, K. (2018). Thinking on Information Construction of Food Safety (in Chinese). China Pharmacist, 21(11), 2013-2016.

8. Hou, Y. M. (2019). Suggestions on how to promote transmission of food quality safety (In Chinese). China Standardization. (19), 170-174.

9. Houser, F. (1973). The issues of the sixties: An exploratory study in the dynamics of public opinion. Public Opinion Quarterly, 37(1), 62-75.

10. Li, X. W., Liu, T. H., \& Lu, Y. M. (2019). Research on public information diffusion behavior of dangerous chemicals based BASS model (in Chinese). Chinese Journal of Management, 16(11), 1703-1711.

11. Liang, L. (2020). Study onrisk communication framework and influencing factors of food safety (in Chinese). Journal of Henan Agricultural University, 54(3), 543-550.

12. Ma, X. N., \& Du, M. H. (2015). Analysis of risk factors and responsibility subjects for food safety in China (In Chinese). Journal of Food Safety and Quality, 6(8), 3167-3171.

13. Manfield, E. (1961). Technological change and the rate of information. Econometrica, 29(4), 741-766.

14. Rajkumar, V., \& Kumar, V. (2002). A genetic algorithms approach to growth phase forecasting of wireless subscribers. International Journal of Forecasting, 18(4), 625-646.

15. Ren, J. C., \& Han, Q. (2017). The diffusion process of food safety information based on heterogeneity of food safety incidents (in Chinese). System Engineering and Practice, 31(11), 2833-2843.

16. Schmittlein, D. C., \& Mahajan, V. (1982). Maximum likelihood estimation for an innovation diffusion model of new product acceptance. Marketing Science, 1(1), 57-78.

17. Srinivasan, V., \& Mason, C. H. (1986). Nonlinear least squares estimation of new product diffusion models. Marketing Science, 5(1), 169-178.

18. Wang, Z. G., Wang, Q. K., \& Wu, L. Y. (2012). Study on main influencing factors of food sfety in China (In Chinese). Quality and Safety of ArgoProducts. (2), 11-21.

19. Yang, J. H., \& Wu, C. Y. (2005). To Compare Two Kinds of Estimates on the Parameters of Bass Model (in Chinese). The Journal of Quantitative and Technical Economics, 12(125-132).

20. Zhu, X. H., Shan, X. G., \& C.J., H. (2011). China internet public opinion analysis report 2011. Beijing: Public Opinion Monitoring Center of People Network. 